\title{
Entropy-Based Set Pair Analysis Model on Geological Disaster Risk for Military Engineering*
}

\author{
Quanbing Rong, Hongjun Zhang, Fengshan Wang \\ Engineering Institute of Engineering Corps., PLA University of Science \& Technology, Nanjing, China \\ Email:WFS919@tom.com
}

Received September 27, 2011; revised December 2, 2011; accepted December 10, 2011

\begin{abstract}
Measuring the geological disaster-risked situation, is a typical non-deterministic decision-making issue in disaster prevention and emergency response science for military engineering. Based on the given geological disaster risk analysis mechanism, geological disaster risk monitoring matrix was established, and risk characters' value was obtained by mining the hidden information in the monitoring matrix with Entropy theory; with Identity, Discrepancy, and Contrary of Set Pair Analysis and distance measurement, geological disaster-risked model was erected for military engineering, and the steps were given for measuring geological disaster risk, which determined geological disaster-risked SPA force and order relationship of military engineering. Finally, case showed that model has the feasibility and effectiveness over measuring the geological disaster-risked situation for military engineering.
\end{abstract}

Keywords: Risk Analysis; Geological Disaster; Military Engineering; Set Pair Analysis; Entropy

\section{Introduction}

Geological disasters are occurred by natural or humaninduced geological environment or geology change, such as collapse, landslide, debris flow, ground fissures, land subsidence, ground collapse, sudden rock burst and the water tunnel etc. [1].

Geological disaster-risked issue was focused widely home and abroad [2], whose purpose was to estimate the damage range and potential impact of geological disaster from disaster-caused factors and pregnant environment, providing the basis for disaster prediction, disaster prevention and even disaster compensation [3]. According to current study of the geological disaster-risked assessment [4], coupled structure and risk assessment logic was proposed about the possibility of the geological disaster body and the vulnerability of risk body, which gave the overall concept from the object, content, purpose and other aspects of geological disaster risk assessment.

Geological disaster was a typical threat faced by military engineering structure, whose destructive effects could easily produce the structural damage phenomenon [5], resulting in complex relationship between risk and security, so it urgently needed recognize the mechanism of geological disaster risk of military engineering, measuring the status of the geological disaster-risked military

*This work is supported by the natural fund of Chinese PLA University of Science and Technology (No.20110308) and the China Postdoctoral Science Foundation (No.20110491844). engineering, and providing support for the protective problem of military engineering.

Measurement of the geological disaster-risked situation for military engineering, has the general rules of the damage and its measurement to military engineering [6], and has the general geological disaster risk assessment rules. Otherwise, this measurement had its uniqueness, needing adapt to the corresponding standard, rule, model, method, system and etc. With SPA model, Gongshi Liang [7] characterized the geological disasters in the uncertainty of the system and its role, whose Identity, Discrepancy, and Contrary force could effectively guide the measurement of the geological disaster-risked status of military engineering, but which needed the improvement to adapt to the geological disaster control features, handling the relationship between the certainty and uncertainty of the geological disaster risk to military engineering.

\section{Characters of Geological Disaster-Risked Military Engineering}

\subsection{Risk Analysis Mechanisms of Geological Disasters about Military Engineering}

Set Pair Analysis (SPA) proposed by K. Q. Zhao [8], carried on the dialectical analysis and mathematical treatment about the certainty and uncertainty within the common system, which reflected the system, differentiation, mathematical characteristics. Integration of SPA and 
Entropy method, tried to measure the stability of military engineering under the geological disaster risk, providing the basis for risk inspection, prevention and emergency response.

Under the geological disaster, the identification of risk class and its influencing factors was the primary work in the entire measuring process on the structure risk of military engineering, to determine the risk characteristics of geological disasters to military engineering.

With the integrated model of SPA and Information Entropy, risk analysis mechanism was established on geological disaster to military engineering, as shown in Figure 1, among which M.E. signed military engineering.

In Figure 1, the risk analysis mechanism on geological disaster for military engineering was in essence to translate the uncertainty of the geological disaster-risked military engineering into the concrete mathematical operations about Information Mining and SPA of risk monitoring information, in order to determine the overall situation and risk SPA force of military engineering.

\subsection{Measure Geological Disaster-Risked Characters of Military Engineering}

Following the risk analysis mechanism on geological disaster for military engineering, $C_{j}$ said the role of geological disaster-risked character or index to military engineering, and its set was $C$,

$C=\left[C_{1}, C_{2}, \cdots, C_{j}, \cdots, C_{n}\right]^{T} \cdot E_{i}$ said the monitoring site of military engineering, and $E$ denoted the set of $E_{i}$, $E=\left\{E_{i} \mid 1 \leq i \leq m\right\}$. Set $x_{i, j}$ as the measurement of the military engineering monitoring site $x_{i, j}$ on the section of index $C_{j}$, and $S_{i}=\left\{x_{i, j} \mid 1 \leq j \leq n\right\}$ denoted as its set, expressing the status of military engineering monitoring $E_{i}$. $\tilde{E}$ was set as the ideal status of military engineering, whose state measurement was denoted as
$\left.\tilde{S}=\left\{x_{m+1, j} \mid 1 \leq j \leq n\right)\right\}$.

On the basis of the monitoring status $S_{i}$ and ideal status $\tilde{S}$ of military engineering, the geological disasterrisked monitoring matrix $X$ was erected for military engineering, such as “(1)”.

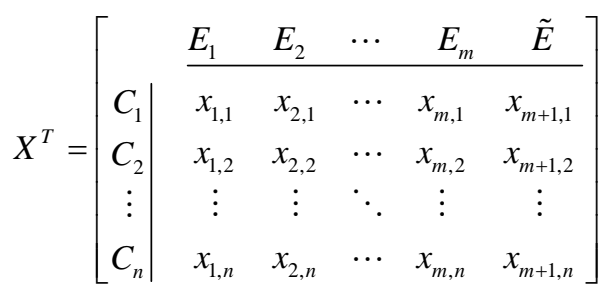

where in "(1)", $X$ was as well as called the initial monitoring matrix about the geological disaster-risked military engineering, which was the quantitative basis for all the follow-up risk analysis works.

\section{Entropy-Based Character Weight and Distance Measurement of the Geological Disaster-Risked Military Engineering}

\subsection{Standardization of Geological Disaster-Risked Characters of Military Engineering}

From the perspective trends of index $C_{j}$ in the risk monitoring system for military engineering, there was max and min mode. Max trend showed that the greater value of $C_{j}$, the more stability of military engineering; Otherwise, min trend showed that the greater value of $C_{j}$, the worse stability. So, the max trend expressed the efficiency in the measurement of the geological disasterrisked military engineering status, and the min trend denoted the cost-based content.

With the minimum method, the geological disasterrisked monitoring matrix $X$ was standardized. If index $C_{j}$ showed the max trend in the risk monitoring system

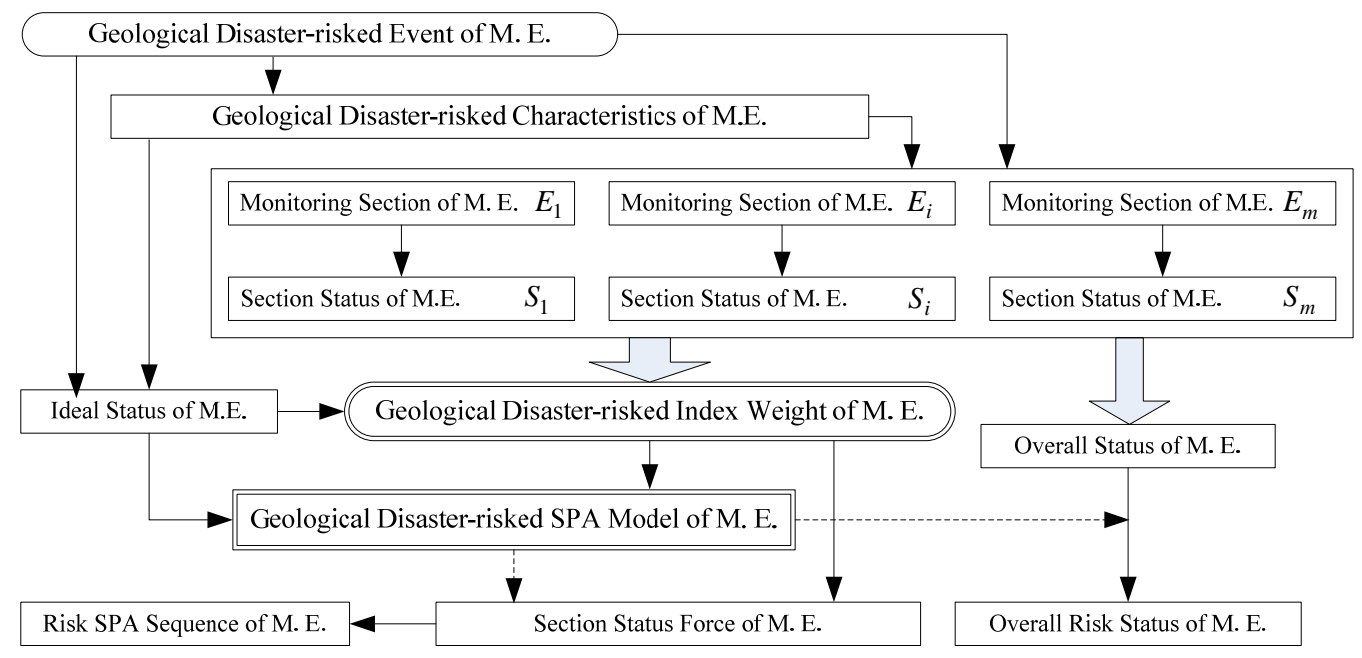

Figure 1. Risk analysis mechanism on geological disaster for military engineering. 
for military engineering, then:

$$
v_{i, j}=x_{i, j} / \max _{1 \leq i \leq m+1}\left(x_{i, j}\right)
$$

If index $C_{j}$ showed the min trend in the risk monitoring system for military engineering, then:

$$
v_{i, j}=\min _{1 \leq i \leq m}\left(x_{i, j}\right) / x_{i, j}
$$

Meanwhile, $E^{-}$was defined as the overall risk status of military engineering under the geological disasters, whose parameters were expressed as

$$
\begin{aligned}
& \left.S^{-}=\left\{x_{m+2, i} \mid 1 \leq i \leq m\right)\right\}, \text { namely: } \\
& x_{m+2, i}=\min _{1 \leq i \leq m+1}\left\{x_{i j}\right\}(j=1,2, \cdots, n)
\end{aligned}
$$

In "(4)", the minimum value was selected as the parameter of the worst state of military engineering, which scaled the overall risk of geological hazards to military engineering of the index measurements

Thus, the geological disaster risk monitoring matrix $X$ was transformed into standardized matrix $\overline{\bar{X}}$ for military engineering, such as “(5)”.

$$
\overline{\bar{X}}^{T}=\left[\begin{array}{c|cccccc} 
& E_{1} & E_{2} & \cdots & E_{n} & \tilde{E} & E^{-} \\
\cline { 2 - 7 } & x_{1,1} & x_{2,1} & \cdots & x_{m, 1} & x_{m+1,1} & x_{m+2,1} \\
C_{2} & x_{1,2} & x_{2,2} & \cdots & x_{m, 2} & x_{m+1,2} & x_{m+2,2} \\
\vdots & \vdots & \vdots & \ddots & \vdots & \vdots & \vdots \\
C_{n} & x_{1, n} & x_{2, n} & \cdots & x_{m, n} & x_{m+1, n} & x_{m+2, n}
\end{array}\right]
$$

\subsection{Entropy-Based Index Weight of Geological Disaster-Risked Military Engineering}

Weight was an important information of risk situation measurement for military engineering under the effect of geological disasters, easily affected by subjective factors, where complexity and uncertainty was existed. Entropy [9] was applied into gaining the weight from the angle of the inner characteristics system and intrinsic relationship under geological disaster risk of military engineering. Entropy weight of the geological disaster risk index could reflect the disorder degree of the index system, and reduce the subjective windage effectively.

Using the standardized geological disaster risk monitoring matrix $\overline{\bar{X}}$ for military engineering, $f_{i, j}$ was set as the proportion of the geological disaster-risked military engineering status $S_{i}$ on the section $C_{j}$, then:

$$
f_{i, j}=x_{i, j} / \sum_{i=1}^{m+2} x_{i, j}
$$

According to Information Entropy method [10,11], the Shannon entropy value was set as $e_{j}$ about the geological disaster-risked index $C_{j}$ for military engineering.

$$
e_{j}=\operatorname{Sh}\left(C_{j}\right)=-\frac{1}{\ln (m+2)} \sum_{i=1}^{m+2} f_{i, j} \ln \left(f_{i, j}\right)
$$

In “(7)”, $e_{j}$ reflected the disorder characteristic of the geological disaster-risked index $C_{j}$ for military engineering. As the most entropy value, the disorder was most in the geological disaster-risked system. If $f_{i, j}=0$ took place, $f_{i, j}=0.00001$ was replaced.

Thus, the weight value was determined for the geological disaster-risked index $C_{j}$ for military engineering, namely:

$$
v_{j}=\left(1-e_{j}\right) /\left(n-\sum_{j=1}^{n} e_{j}\right), \sum_{j=1}^{n} v_{j}=1
$$

where, $v_{j}$ denoted the weight value of the geological disaster-risked index $C_{j}$. Additionally, $\tilde{V}$ was the set of $v_{j}, \tilde{V}=\left\{v_{j} \mid j=1,2, \cdots, n\right\}$.

\subsection{Distance Measurement of the Geological Disaster-Risked Military Engineering}

According to the geological disaster risk status of $S_{1}$, $S_{2}, \cdots, S_{m}, S_{m+1}, S_{m+2}$ for military engineering, $\operatorname{dis}\left(S_{i}, \tilde{S}\right) \quad(1 \leq i \leq m+2)$ was denoted as the proximity from the risk status $S_{i}$ to the ideal status $\tilde{S}$, which could be weighted by Minkowski distance, namely:

$$
\operatorname{dis}\left(S_{i}, \tilde{S}\right)=\left\{\sum_{j=1}^{n}\left[v_{j}\left(x_{i j}-x_{m+1, j}\right)\right]^{2}\right\}^{1 / 2}
$$

Accordingly, $\operatorname{dis}\left(S_{i}, S^{-}\right)(1 \leq i \leq m+2)$ was denoted as the proximity from the risk status $S_{i}$ to the worst status $S^{-}$, which could be expressed as:

$$
\operatorname{dis}\left(S_{i}, S^{-}\right)=\left\{\sum_{j=1}^{n}\left[v_{j}\left(x_{i j}-x_{m+2, j}\right)\right]^{2}\right\}^{1 / 2}
$$

where, “(9)” and “(10)” separately expressed the distance measurement from the risk status $S_{i}$ to the ideal status $\tilde{S}$ and worst status $S^{-}$, in which the meaning of $v_{j}$ consisted with “(8)".

Let $\mathrm{dis}^{+}$and $\mathrm{dis}^{-}$separately as the maximum distance measurement from the risk status $S_{i}$ to the ideal status $\tilde{S}$ and overall status $S^{-}$, as shown in "(11)".

$$
\left\{\begin{array}{l}
\operatorname{dis}^{+}=\max _{i=1,2, \cdots, m+2}\left\{\operatorname{dis}\left(S_{i}, S^{+}\right)\right\} \\
\operatorname{dis}^{-}=\max _{i=1,2, \cdots, m+2}\left\{\operatorname{dis}\left(S_{i}, S^{-}\right)\right\}
\end{array}\right.
$$

\section{Geological Disaster-Risked SPA Model for Military Engineering}

\subsection{SPA Coefficients of the Geological Disaster-Risked Situation of Military Engineering}

Under the background of geological disaster risk analysis problem of military engineering, $H_{i}$ was established as the geological disaster-risked SPA of military engineer- 
ing, as shown in “(12)”.

$$
H_{i}=h\left(\tilde{S}, S_{i}\right), i=1,2, \cdots, m, m+2
$$

That is, the risk status SPA was made up of the geological risk $S_{i}$ and the ideal status $\tilde{S}$ about military engineering.

According to the extraction and analysis about the geological disaster-risked characteristics of military engineering, SPA $H_{i}$ had $n$ features or indexes. Of these, there were $a l_{i}$ units in the identity, there were $a g_{i}$ units in the contrary, and there were $a t_{i}$ units in the discrepancy of Set $\tilde{S}$ and Set $S_{i} . a l_{i}, a g_{i}$, and $a t_{i}$ must satisfy:

$$
a t_{i}+a g_{i}+a l_{i}=n
$$

According to the basic principle of SPA [8], $\mu_{i}$ was defined as the connection degree of the geological disaster-risked SPA $h\left(\tilde{S}, S_{i}\right)$ for military engineering, as shown in "(14)".

$$
\mu_{i}=\frac{a l_{i}}{n}+\frac{a t_{i}}{n} \boldsymbol{\alpha}+\frac{a g_{i}}{n} \boldsymbol{\beta}
$$

Here, $a l_{i} / n$ was identity, $a t_{i} / n$ was discrepancy, and $a g_{i} / n$ was contrary. And, $\boldsymbol{\alpha}$ was the coefficient for discrepancy, which was restrained in $\boldsymbol{\alpha} \in[-1,1] ; \boldsymbol{\beta}$ was the coefficient for contrary, which was defined as $\boldsymbol{\beta}=-1$.

Defined $a_{i}=a l / n, b_{i}=a t / n$, and $c_{i}=a g / n$. Following the connection degree of the geological disasterrisked SPA $h\left(\tilde{S}, S_{i}\right), g\left(\mu_{i}\right)$ was established as the geological disaster-risked SPA function for military engineering, as shown in "(15)".

$$
g\left(\mu_{i}\right)=a_{i}+b_{i} \boldsymbol{\alpha}+c_{i} \boldsymbol{\beta}
$$

\subsection{Coefficient Calculation about Military Engineering's Geological Disaster-Risked SPA}

According to the distance measurement $\operatorname{dis}\left(S_{i}, \tilde{S}\right)$ and $\operatorname{dis}\left(S_{i}, S^{-}\right)$of the geological disaster-risked military engineering, $U_{i}$ was made as the uncertain measurement in the geological disaster-risked military engineering SPA function.

$$
U_{i}=\left\{\sum_{j=1}^{n}\left[v_{j}\left(2 x_{i j}-x_{m+1, j}-x_{m+2, j}\right)\right]^{2}\right\}^{1 / 2}
$$

According to Minkowski inequality, existed:

$$
U_{i} \leq \operatorname{dis}^{+}+\operatorname{dis}^{-}
$$

Through the function and distance measurement of the geological disaster-risked military engineering SPA $h\left(\tilde{S}, S_{i}\right)$, the coefficients about $a_{i}, b_{i}, c_{i}$ could be made, as shown in "(18)".

$$
\left\{\begin{array}{l}
c_{i}=\left(\operatorname{dis}\left(S_{i}, \tilde{S}\right)-\operatorname{dis}^{-}\right) /\left(\operatorname{dis}^{+}+U_{i}\right) \\
b_{i}=U_{i} /\left(\operatorname{dis}^{+}+U_{i}\right) \\
a_{i}=\left(\operatorname{dis}^{+}+\operatorname{dis}^{-}-\operatorname{dis}\left(S_{i}, \tilde{S}\right)\right) /\left(\operatorname{dis}^{+}+U_{i}\right)
\end{array}\right.
$$

\subsection{SPA Force of the Geological Disaster-Risked Military Engineering}

As $c_{i} \neq 0$ in the connection degree of $g\left(\mu_{i}\right)$, the ratio $a_{i} / c_{i}$ about the identity $a_{i}$ to the contrary $c_{i}$ was set as the force of the geological disaster-risked military engineering SPA under this risk measuring problem, namely:

$$
\operatorname{Shi}\left(H_{i}\right)=a_{i} / c_{i}
$$

Make the sequence of the geological disaster-risked military engineering SPA by the value of $a_{i} / c_{i}$. Based on the information of $a_{i}, b_{i}, c_{i}$, and with the principle of permutation and combination, the situation of Identity, Discrepancy, and Contrary was analyzed and sorted in Table 1.

\subsection{SPA Analysis Steps about the Geological Disaster Risk of Military Engineering}

There were mainly eight steps in the SPA analysis about the geological disaster risk of military engineering.

Step 1: Demonstrate the geological disaster risked characteristics of military engineering, and establish the geological disaster-risked monitoring matrix $X$.

Step 2: The geological disaster-risked monitoring matrix $X$ was standardized according to "(2)" and “(3)”.

Step 3: According to "(4)", determine the overall status (the worst status) $S^{-}$of the geological disasterrisked military engineering, then establish the standardized geological disaster-risked matrix $X$.

Step 4: According to “(6)", "(7)” and “(8)", determined the index Entropy and weight value of the geological disaster-risked military engineering.

Step 5: According to "(9)" and "(10)", determine the distance measurement $\operatorname{dis}\left(S_{i}, \tilde{S}\right)$ and $\operatorname{dis}\left(S_{i}, S^{-}\right)$of the geological disaster-risked status $S_{i}$ of military engineering $E_{i}$.

Step 6: According to "(11)", determine the maximum distance measurement $\mathrm{dis}^{+}$and $\mathrm{dis}^{-}$of the status $S_{i}$ of the geological disaster-risked military engineering $E_{i}$.

Step 7: For each status $S_{i}$ of the geological disasterrisked military engineering $E_{i}$, “(18)” was applied into reckoning the identity $a_{i}$, discrepancy $b_{i}$, and contrary $c_{i}$.

Step 8: Calculate the force $\operatorname{Shi}\left(H_{i}\right)$ of the geological disaster-risked military engineering SPA, select the corresponding degree from Table 1, analyze the overall geological disaster-risked status of military engineering, 
Table 1. Geological disaster-risked SPA force degree and order relationship on military engineering.

\begin{tabular}{cccc}
\hline Item & Comparison of $a_{i}, b_{i}$, and $c_{i}$ & SPA Force Grade & SPA Force \\
\hline 1. Level & $a_{i}>c_{i}, b_{i} \leq c_{i}$ & Common Force & Strong Common Force \\
2. Level & $a_{i}>c_{i}, c_{i}<b_{i} \leq a_{i}$ & Normal Common Force \\
3. Level & $\left.a_{i}>c_{i}, b_{i}>a_{i}>1\right)$ & Weak Common Force \\
1. Level & $a_{i}=c_{i}, a_{i}>b_{i}$ & & Strong Equal Force \\
2. Level & $a_{i}=c_{i}=b_{i}$ & $\left(a_{i} / c_{i}=1\right)$ & Normal Equal Force \\
3. Level & $a_{i}=c_{i}, a_{i}<b_{i}$ & & Weak Equal Force \\
1. Level & $a_{i}<c_{i}, a_{i} \geq b_{i}$ & Contrary Force & Strong Contrary Force \\
2. Level & $a_{i}<c_{i}, a_{i}<b_{i} \leq c_{i}$ & Normal Contrary Force \\
3. Level & $a_{i}<c_{i}, b_{i}>c_{i}$ & & Weak Contrary Force \\
\hline
\end{tabular}

and determine the sequence of the geological disasterrisked sections of military engineering.

\section{Application Example}

\subsection{Monitoring Parameters Example on the Geological Risk of Military Engineering}

Assuming under the earthquake-induced landslide risk, referring to the emergency, rock landslides other risk characteristics [12-15], the risk features of geological military engineering was demonstrated by Single Axis Saturated Resisting Intensity, Risk Probability, maneuverability, Maximum terra stress, and others, as shown in Table 2. Meanwhile, max and min denoted the trend of the risk characteristics of the geological landslide-threatened military engineering.

Designed the important monitoring slope part of military engineering, whose status parameters were $S_{1}, S_{2}$, $S_{3}, S_{4}, S_{5}$, and whose ideal status was $\tilde{S}$.

\subsection{Standardization and Entropy Weights of Risk Case}

After studying on the trend of the geological disasterinduced landslide risk index of military engineering, the standardized matrix $\overline{\bar{X}}$ was established for the geological disaster-risked case of military engineering with the formula "(2)" and "(3)". With "(4)", the overall geological disaster-risked landslide status $S^{-}$was determined for military engineering, as shown in Table 3.

According to "(6)", “(7)", and "(8)", the index entropy and weight value was calculated for the geological disasterrisk case for military engineering, as shown in Table 4.

\subsection{Distance of the Geological Disaster-Risked Military Engineering Case}

In accordance with the "(9)”, “(10)”, “(16)”, the distance of geological disaster-risk case on military engineering was determined, as shown in Table 5.

According to the "(11)", the maximum distance of geological disaster-risk case was calculated as dis $^{+}=0.198$, dis $^{-}=0.0664$.

\subsection{SPA Coefficients about Geological Disaster-Risked Military Engineering Case}

In accordance with "(18)" and "(19)", the SPA coefficients and force was determined for the geological disaster-risked military engineering case, as shown in Table 6.

According to Table 6, the SPA force of the geological disaster-risked military engineering case showed, $\operatorname{Shi}\left(H_{4}\right)>\operatorname{Shi}\left(H_{3}\right)>\operatorname{Shi}\left(H_{5}\right)>\operatorname{Shi}\left(H_{2}\right)>\operatorname{Shi}\left(H_{1}\right)$, where $E_{1}$ was the key risk monitoring section, and $E_{4}$ viewed the relative most security. Based on the geological disaster-risk SPA force degree and order relationship on military engineering, as Table $1, E_{4}$ and $E_{3}$ met the weak equal force $\left(a_{i}>c_{i}, b_{i}>a_{i}\right)$, namely the status of $E_{4}$ and $E_{3}$ tended to the weak identity towards to the stability of the ideal state of military engineering. Otherwise, $E_{5}, E_{2}$ and $E_{1}$ met the weak contrary force $\left(a_{i}<c_{i}, b_{i}>c_{i}\right)$, namely the status of $E_{5}, E_{2}$ and $E_{1}$ tended to the weak contrary towards to the stability of the ideal status of military engineering. Finally, the SPA force of the overall geological disaster-risked military engineering case $E^{-}$was $\operatorname{Shi}\left(H^{-}\right)=0.5425$, which reflected the overall risk degree of the geological disasterrisked military engineering was in the weak contrary force, and viewed the general risk threat.

\section{Conclusions}

There were many factors affecting the geological disaster-risked military engineering, how to effectively measure the geological disaster-risked military engineering 
Table 2. Character parameters of geological disaster-risked case for military engineering.

\begin{tabular}{|c|c|c|c|c|c|c|c|c|c|c|c|c|c|}
\hline & SAS & RS & $\mathrm{RM}$ & RIC & $\mathrm{CO}$ & $\mathrm{RP}$ & UR & MA & IFA & SA & SDR & MTS & DP \\
\hline & $\max$ & $\max$ & $\max$ & $\max$ & $\max$ & $\min$ & $\min$ & $\max$ & $\max$ & $\min$ & $\min$ & $\min$ & $\min$ \\
\hline$S_{1}$ & 65 & 48 & 7.3 & 0.56 & 0.40 & 0.56 & 0.52 & 2.0 & 38 & 21 & 0.21 & 12.8 & 0.24 \\
\hline$S_{2}$ & 41 & 56 & 11.2 & 0.49 & 0.38 & 0.29 & 0.68 & 3.0 & 40 & 15 & 0.23 & 11.3 & 0.19 \\
\hline$S_{3}$ & 53 & 39 & 7.8 & 0.64 & 0.25 & 0.42 & 0.49 & 4.0 & 25 & 9 & 0.35 & 8.3 & 0.18 \\
\hline$S_{4}$ & 70 & 74 & 6.9 & 0.71 & 0.19 & 0.36 & 0.37 & 3.0 & 32 & 13 & 0.18 & 3.9 & 0.26 \\
\hline$S_{5}$ & 59 & 50 & 5.4 & 0.55 & 0.30 & 0.48 & 0.55 & 2.0 & 49 & 12 & 0.13 & 10.4 & 0.25 \\
\hline$\tilde{S}$ & 80 & 80 & 12.5 & 0.82 & 0.35 & 0.25 & 0.25 & 5.0 & 45 & 5 & 0.02 & 4.5 & 0.05 \\
\hline
\end{tabular}

Note: SAS—Single Axis Saturated Resisting Intensity; RS—Rock Structure; RM—Rock Mass Deformation Modulus; RIC—Rock Integrity Coefficient; CO_ Cohesion; RP—Risk Probability; UR_Urgency; MA—Maneuverability; IFA—Internal Friction Angle; SA—Slope Angle; SDR—Surface Deformation rate; MTS-Maximum Terra Stress; DP_Drainage Performance.

Table 3. Standardized matrix of geological disaster-risked case for military engineering.

\begin{tabular}{ccccccccccccccc}
\hline & SAS & RS & RM & RIC & CO & RP & UR & MA & IFA & SA & SDR & MTS & DP \\
\hline$S_{1}$ & 0.8125 & 0.6000 & 0.5840 & 0.6829 & 1.0000 & 0.4464 & 0.4808 & 0.4000 & 0.7755 & 0.2381 & 0.0952 & 0.3047 & 0.2083 \\
$S_{2}$ & 0.5125 & 0.7000 & 0.8960 & 0.5976 & 0.9500 & 0.8621 & 0.3676 & 0.6000 & 0.8163 & 0.3333 & 0.0870 & 0.3451 & 0.2632 \\
$S_{3}$ & 0.6625 & 0.4875 & 0.6240 & 0.7805 & 0.6250 & 0.5952 & 0.5102 & 0.8000 & 0.5102 & 0.5556 & 0.0571 & 0.4699 & 0.2778 \\
$S_{4}$ & 0.8750 & 0.9250 & 0.5520 & 0.8659 & 0.4750 & 0.6944 & 0.6757 & 0.6000 & 0.6531 & 0.3846 & 0.1111 & 1.0000 & 0.1923 \\
$S_{5}$ & 0.7375 & 0.6250 & 0.4320 & 0.6707 & 0.7500 & 0.5208 & 0.4545 & 0.4000 & 1.0000 & 0.4167 & 0.1538 & 0.3750 & 0.2000 \\
$\tilde{S}$ & 1.0000 & 1.0000 & 1.0000 & 1.0000 & 0.8750 & 1.0000 & 1.0000 & 1.0000 & 0.9184 & 1.0000 & 1.0000 & 0.8667 & 1.0000 \\
$S^{-}$ & 0.5125 & 0.4875 & 0.4320 & 0.5976 & 0.4750 & 0.4464 & 0.3676 & 0.4000 & 0.5102 & 0.2381 & 0.0571 & 0.3047 & 0.1923 \\
\hline
\end{tabular}

Table 4. Index Entropy and weight value of geological disaster-risk case for military engineering.

\begin{tabular}{cccccccccccccc}
\hline & SAS & RS & RM & RIC & CO & RP & UR & MA & IFA & SA & SDR & MTS & DP \\
\hline Entropy & 0.9883 & 0.6727 & 0.5095 & 0.4543 & 0.3890 & 0.3143 & 0.2527 & 0.2466 & 0.2633 & 0.1711 & 0.0884 & 0.1748 & 0.1153 \\
Weight & 0.0014 & 0.0392 & 0.0587 & 0.0653 & 0.0731 & 0.0820 & 0.0894 & 0.0901 & 0.0881 & 0.0992 & 0.1090 & 0.0987 & 0.1058 \\
\hline
\end{tabular}

Table 5. Distance calculating of geological disaster risk case.

\begin{tabular}{ccccccc}
\hline & $S^{-}$ & $S_{1}$ & $S_{2}$ & $S_{3}$ & $S_{4}$ & $S_{5}$ \\
\hline $\operatorname{dis}\left(S_{i}, \tilde{S}\right)$ & 0.1980 & 0.1849 & 0.1691 & 0.1611 & 0.1598 & 0.1736 \\
$\operatorname{dis}\left(S_{i}, S^{-}\right)$ & 0 & 0.0477 & 0.0664 & 0.0578 & 0.0852 & 0.0538 \\
$U_{i}$ & 0.1980 & 0.1836 & 0.1638 & 0.1392 & 0.1625 & 0.1640 \\
\hline
\end{tabular}

Table 6. SPA coefficient of geological disaster-risk case.

\begin{tabular}{ccccccc}
\hline & $S^{-}$ & $S_{1}$ & $S_{2}$ & $S_{3}$ & $S_{4}$ & $S_{5}$ \\
\hline$a_{i}$ & 0.1782 & 0.2187 & 0.2735 & 0.3165 & 0.2999 & 0.2611 \\
$b_{i}$ & 0.4934 & 0.4745 & 0.4462 & 0.4064 & 0.4442 & 0.4465 \\
$c_{i}$ & 0.3284 & 0.3068 & 0.2803 & 0.2771 & 0.2559 & 0.2924 \\
$\operatorname{Shi}\left(H_{i}\right)$ & 0.5425 & 0.7127 & 0.9757 & 1.1423 & 1.1720 & 0.8929 \\
\hline
\end{tabular}

was the systemic issues in the scientific research of the disaster-risked emergency and prevention for military engineering. SPA model of the geological disaster-risked military engineering, was the most directly served into the order for the geological disaster-risked sections of military engineering, which could relief conflicts between emergences resource and engineering requirement, providing relevant helps to organize or command the repair problem.

1) A brief analysis to the value of the geological risk measurement of military engineering, put forward the measuring features of geological disaster-risked status of military engineering; The exploration to the characteristic of index parameters and variation trend, proposed the standardized method for risk index parameters, and established the standardized matrix of geological disasterrisked military engineering. 
2) SPA model of the geological disaster-risked military engineering, put forward the work steps for the geological disaster-risked SPA status of military engineering, and quantitatively analyzed the certainty and uncertainty between the monitoring section and ideal status of the geological disaster-risked military engineering.

3) Integrated entropy coefficient method was used to determine the weight of the geological disaster-risked index of military engineering, whose information was adequate and reliable highly. Model and algorithm was easily realized by computer software, and achieved good results, had been integrated and applied into a geological disaster emergency decision support system of military engineering.

4) Example showed that, integrated model of Entropy and SPA method, fully mined, reflect and used the implied weight information of the risk monitoring sample of military engineering, which effectively improved the decision-making of the geological disaster-risked status of military engineering. However, how to evaluate the core factor of the geological disaster-risked index system of military engineering, needed the further exploration, and stood at the principle as special issue need special analysis.

\section{REFERENCES}

[1] H. P. Xiao and F. X. Pan, "Geological Hazard and Hazard Prevention,” Beijing, 2000.

[2] Q. H. Song, D. S. Liu, Y. Wu, et al., "Comprehension and Discussion on Some Basic Concepts about Geo-Hazards Risk Assessment and Management," Chinese Journal of Underground Space and Engineering, Vol. 4, No. 6, 2008, pp. 1177-1182.

[3] F. F. Liu and J. X. Zou, "The Content Method and Development of Geo-Hazards Evaluation,” Chinese Journal of Hebei Institute of Technology, Vol.28, No. 4, 2006, pp. 126-129. doi:1007-2829(2006)04-0126-04

[4] S. R. Wu, J. S. Shi, C. S. Zhang, et al., "Preliminary Discussion OR Technical Guideline for Geohazard Risk Assessment,” Geological Bulletin of China, Vol. 28, No. 8, 2009, pp. 995-1005.

[5] F. S. Wang and H. J. Zhang, "Damage Evaluation Modeling on Military Engineering based on UML,” Application Research of Computers, Vol. 27, No. S1, 2010, pp. 648-649.
[6] F. S. Wang, W. H. Zhu and H. Q. Lu, “Decision-Making Modeling of Military Engineering Repair Operations Based on Organizational Design,” 2010 International Colloquium on Computing, Communication, Control, and Management, Vol. 1, Yangzhou, 20-22 August 2010, pp. 1221-224.

[7] S. L. Gong, "SPA of Risk Assessment of Secondary Disasters of Earthquake,” Acta Geological Sichuan, Vol. 30, No. 1, 2010, pp. 118-122.

[8] K. Q. Zhao, "Set Pair Analysis and Applications,” Hangzhou, 2000.

[9] Y. Horibe, “Entropy and Correlation,” IEEE Transactions on Systems, Man and Cybernetics, Vol. SMC-15, No. 5, 1985, pp. 641-642.

[10] F. S. Wang, Y. Cao and M. Liu. "Risk Early-Warning Method for Natural Disasters Based on Integration of Entropy and DEA Model," Journal of Applied Mathematics, Vol. 2, No. 1, 2011, pp. 23-32. doi:10.4236/am.2011.21003

[11] L. S. Qu, L. M. Li and J. Lee, "Enhanced Diagnostic Certainty Using Information Entropy Theory,” Advanced Engineering Information, Vol. 17, No. 3-4, 2003, pp. 141150. doi:10.1016/j.aei.2004.08.002

[12] X. L. Tan, W. Y. Xu and G. L. Liang, "Application of Extenics Method to Comprehensive Safety Evaluation of Rock Slope," Chinese Journal of Rock Mechanics and Engineering, Vol. 28, No. 12, 2009, pp. 2503-2509. doi:1000-6915(2009)12-2503-07

[13] K. T. Lee and J. Y. Ho, "Prediction of Landslide Occurrence Based on Slope-Instability Analysis and Hydrological Model Simulation,” Journal of Hydrology, Vol. 375, No. 3-4, 2009, pp. 489-497. doi:10.1016/j.jhydrol.2009.06.053

[14] L. Pantelidis, "Rock Slope Stability Assessment through Rock Mass Classification Systems," International Journal of Rock Mechanics \& Mining Sciences, Vol. 46, No. 2, 2009, pp. 315-325. doi:10.1016/j.ijrmms.2008.06.003

[15] R. L. Chen and Z.-X. Zeng, "Method of Entropy Coefficient to Evaluate the Surrounding Rock Stability of Underground Engineering," Journal of Huaqiao University (Natural Science), Vol. 29, No. 3, 2008, pp. 443-446. doi:00-5013(2008)03-0443-04

[16] F. S. Wang, L. He, M. Liu, et al., "A Landslide Risk Early-Warning Method in Urgent Repair Operations for Earthquake-Damaged Underground Engineering,” 2010 IEEE International Conference on Intelligent Computing and Intelligent Systems, Guangzhou, 18-20 November 2011, pp. 576-580. doi:10.1109/ICICISYS.2010.5658402 